\title{
Cerebral Monitoring in the OR and ICU
}

Edited by Enno Freye

Reprinted from Journal of Clinical Monitoring and Computing, Volume 19, Nos. 1-2, 2005

照 Springer 
Library of Congress Cataloging-in-Publication Data

A. C.I.P. Catalogue record for this book is available from the Library of Congress

ISBN 1-4020-3162-9

Published by Springer,

P.O. Box 17, 3300 AA Dordrecht, The Netherlands.

Sold and distributed in the U.S.A. and Canada

by Springer,

101 Philip Drive, Norwell, MA 02061, U.S.A.

In all other countries, sold and distributed

by Springer,

P.O. Box 322, 3300 AH Dordrecht, The Netherlands.

\section{Printed on acid-free paper}

All Rights Reserved

(C) 2005 Springer

No part of the material protected by this copyright notice may be reproduced or utilized in any form or by any means, electronic or mechanical, including photocopying, recording or by any information storage and retrieval system, without written permission from the copyright owner.

Printed in the Netherlands 


\section{TABLE OF CONTENTS}

Preface

ENNO FREYE, MD, PhD and JOSEPH V. LEVY, PhD / Cerebral Monitoring in the Operating Room and the Intensive Care Unit: An Introductory for the Clinician and a Guide for the Novice Wanting to Open a Window to the Brain. Part I: The Electroencephalogram

ENNO FREYE, MD, PhD / Cerebral Monitoring in the Operating Room and the Intensive Care Unit: An Introductory for the Clinician and a Guide for the Novice Wanting to Open a Window to the Brain. Part II. Sensory-Evoked Potentials (SSEP, AEP, VEP)

ENNO FREYE, MD, PhD / Cerebral Monitoring in the Operating Room and the Intensive Care Unit: An Introductory for the Clinician and a Guide for the Novice Wanting to Open a Window to the Brain. Part III: Spinal Cord Evoked Potentials 


\section{PREFACE}

The evaluation of an ICU patient's degree of consciousness has taken on great importance. The problem of unintended intraoperative rivival and compensation has resulted in the need for monitoring the level of unconsciousness with instruments that measure the patient's cerebral activity rather than vital signs (arterial pressure, cardiac rate, tear secretion, etc.). In addition, the need for salvaging organs for transplantation requires the anesthesiologist to understand cerebral mechanisms to diagnose brain death before the disappearance of vital signs which renders the organs useless for transplantation. In the final analysis the physician has had to change his vision of cortical activity considered, if not strictly indispensible, at least of secondary importance relative to the hemodynamic consequences to the patient. The problem is even more complex in those nations where the teaching of anesthesia and reanimation is combined, presenting the physician with the twofold chore of cerebral monitoring to prevent intraoperative awakening and to detect brain death.

Technological innovation has created simple, precise instruments to replace ECG devices which are subject to artifacts caused by patient movement or interference from other electronic instruments in the operating room or ICU. However, the use of modern devices such as the bis-monitor, entropy, etc. is not widely taught in university courses, forcing the anesthesiologist to embark on a disorganized study of the various instruments, often not accompanied by an understanding of cerebral activity. Prof. Freye's book is an organized treatment of cerebral activity which offers a clear explanation of the generation of cerebral impulses and the potential value that cerebral monitoring holds for patients. Although many complex algorithms appear in the book, the text explains modern monitoring techniques with such simplicity that even physicians with little knowledge of mathematics and physics will easily understand the subject. Moreover, the study of evoked potentials, which is invaluable in orthopedic surgery and many other pathologies treated in Intensive Care, is presented clearly and logically. Attractive graphics contribute to the pleasure of reading the book, making the subject less tiring for readers who are confronting the subject for the first time. Physicians who are accustomed to using the ECG will also find that the close examination of this topic alone makes the book worthwhile.

The Journal of Clinical Monitoring and Computing is pleased to present Prof. Freye's book because it is in perfect harmony with our publication's goal of assisting clinicians in the daily use of the most advanced monitoring and computer techniques in patient care.

Vincenzo Lanza

Editor-in-Chief, Journal of Clinical Monitoring and Computing 